\title{
Application of Transmetallation to the Synthesis of Planar Chiral and Chiral-at-Metal Iridacycles
}

\author{
Ross A. Arthurs,\# David L. Hughes,\# Peter N. Horton,§ Simon J. Coles ${ }^{\S}$ and Christopher J. Richards"\# \\ \#School of Chemistry, University of East Anglia, Norwich Research Park, Norwich, NR4 7TJ, U.K. \\ §EPSRC National Crystallography Service, School of Chemistry, University of Southampton, Highfield, Southampton, \\ S017 1BJ, U. K.
}

\begin{abstract}
Diastereoselective lithiation of (S)-2-ferrocenyl-4-(1-methylethyl)oxazoline followed by addition of $\mathrm{HgCl}_{2}$ resulted in the formation by transmetallation of an $\left(S, S_{\mathrm{p}}\right)$-configured mercury substituted complex. Addition to this of $\left.\left[\mathrm{Cp}^{*} \operatorname{IrCl}\right]_{2}\right]_{2}$ and tetrabutylammonium chloride resulted in a second transmetallation reaction and formation of an $\left(S, S_{\mathrm{p}}, R_{\mathrm{Ir}}\right)$-configured chloride-substituted half-sandwich iridacycle as exclusively a single diastereoisomer. By reversing the lithiation diastereoselectivity by use of a deuterium blocking group an alternative $\left(S, R_{\mathrm{p}}, S_{\mathrm{Ir}}\right)$-configured iridacycle was synthesised similarly. Use of $(R)$-Ugi's amine as substrate in the lithiation/double transmetallation sequence gave a $\left(R, S_{\mathrm{p}}, S_{\mathrm{Ir}}\right)$-configured half-sandwich iridacycle, complexes of this type being previously unavailable by direct cycloiridation. Lithium to gold transmetallation was also demonstrated with the synthesis of an $\left(S, S_{\mathrm{p}}\right)$-configured $\mathrm{Au}(\mathrm{I})$ ferrocenyloxazoline derivative. Use of the $\left(S, R_{\mathrm{p}}, S_{\mathrm{Ir}}\right)$-iridacycle as a catalyst for the formation of a chiral product by reductive amination with azeotropic $\mathrm{HCO}_{2} \mathrm{H}_{/} \mathrm{NEt}_{3}$ resulted in a racemate.
\end{abstract}

\section{INTRODUCTION}

Metallacycles derived from late transition metals have been studied extensively as catalysts and pre-catalysts for use in synthesis. ${ }^{1}$ Much of this work has focused on non-racemic metallacycles displaying planar chirality, ${ }^{2}$ including examples that have found application in asymmetric catalysis. $^{3}$ The element of planar chirality is typically generated with relative ease by diastereoselecive ortho-C-H activation mediated by a chiral auxiliary attached to a suitable substrate, such as ferrocene (Scheme 1 - (a)). ${ }^{4}$ Transmetallation has also been used for the synthesis of metallacycles, ${ }^{5}$ this providing an alternative approach where direct access by $\mathrm{C}$ $\mathrm{H}$ activation is not possible. However, the use of transmetallation for the synthesis of planar chiral metallacycles is rare (Scheme 1 - (b)). ${ }^{6}$

Scheme 1. General approaches to the synthesis of planar chiral ferrocene-based metallacycles.
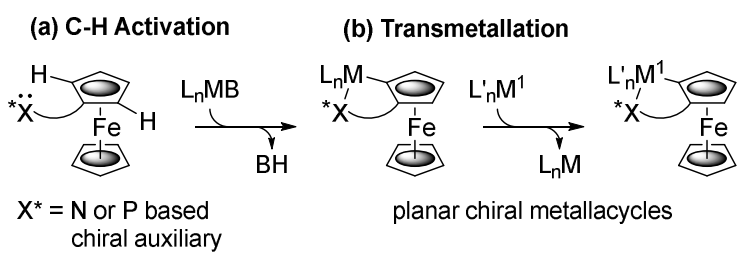

We recently reported the synthesis of planar-chiral iridacycles by diastereoselective $\mathrm{C}$ - $\mathrm{H}$ activation of ferrocenyloxazolines. ${ }^{7}$ In addition to a new element of planar chirality, this also results in an iridium-based stereogenic center, the configuration of the former controlling the configuration of the latter as exemplified by the formation of $\left(S, S_{\mathrm{p}}, S_{\mathrm{Ir}}\right)-\mathbf{2}$ from $(S)-1$ (Scheme 2). This methodology was subsequently extended to planar-chiral iridacycles containing a bulky cobalt-based sandwich complex. ${ }^{8}$ Although successful, C-H activation in this way does limit the structure of the iridacycle with respect to relative stereochemistry of the product, and the identity of the auxiliary employed. Therefore, as a potentially more versatile approach, transmetallation was investigated for the synthesis of planar-chiral iridacycles. The results of this investigation are reported in this Article.

Scheme 2. Diastereoselective cycloiridation of ferrocenyloxazoline $(S)-1$. $^{7}$

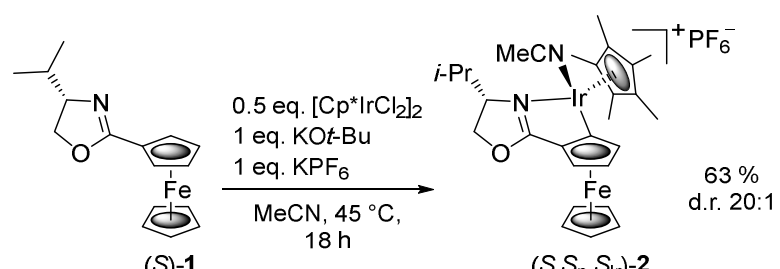

\section{RESULTS AND DISCUSSION}

Transmetallation typically involves the transfer of an alkyl or aryl group from an electropositive metal to a metal with an electronegativity closer to the value for carbon. Simultaneous formation of a more polar by-product, typically a halide salt, from the electropositive metal provides the driving 
force for the reaction. ${ }^{9}$ Use of lithium as the electropositive metal is attractive given the ubiquity of lithiation as a method of $\mathrm{C}-\mathrm{H}$ activation, albeit that the use of organolithiums in this way may alternatively result in reduction of the transmetallation partner. ${ }^{10}$ As conditions have been reported for the highly diastereoselective lithiation of ferrocenyloxazoline $(S)-\mathbf{1}, 11$ this reaction was repeated followed by the addition of $\left[\mathrm{Cp}^{*} \mathrm{IrCl}_{2}\right]_{2}$ in an attempted transmetallation reaction No iridacycle was observed and the starting material $(S)$-1 was recovered from the reaction. In contrast, diastereoselective lithiation followed by the addition of $\mathrm{HgCl}_{2}$ did lead to transmetallation and isolation of mercury substituted ferrocenyl oxazoline $\left(S, S_{\mathrm{p}}\right)-\mathbf{3}$ (Scheme 3$)$. The structure of this complex was confirmed by an X-ray crystallographic analysis (Figure 1). A small quantity of a second product was also isolated (16\% yield) resulting from double transmetallation of $\mathrm{HgCl}_{2}$ with two equivalents of lithiated ferrocenyl oxazoline (see supporting information).

Scheme 3. Diastereoselective lithiation of $(S)-1$ and transmetallation with $\mathrm{HgCl}_{2}$.
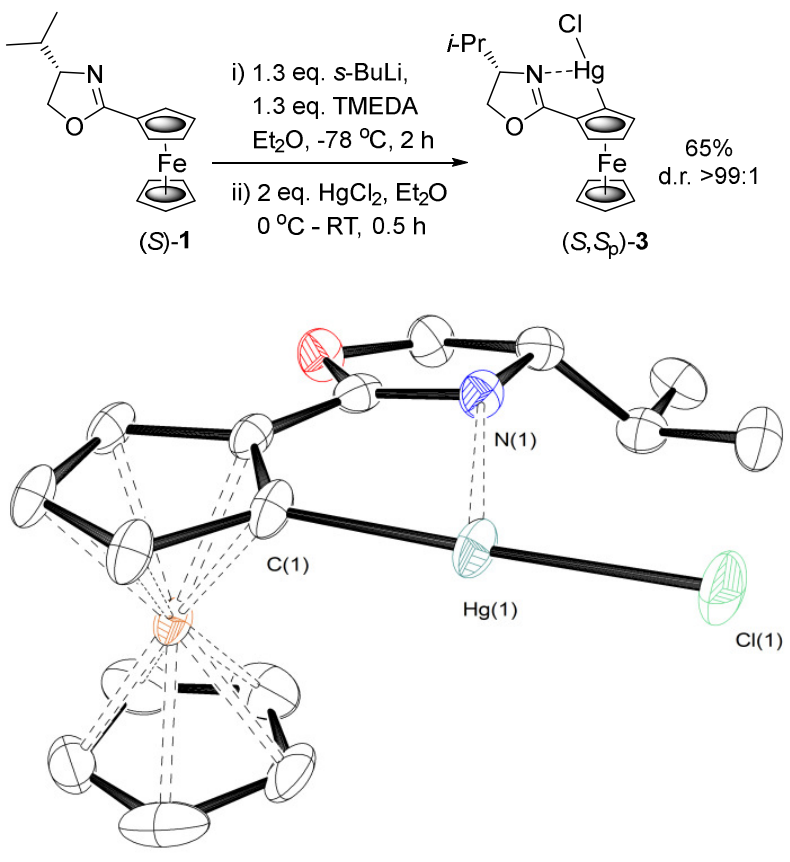

Figure 1. A representation of the X-ray structure of $\left(S, S_{\mathrm{p}}\right)-\mathbf{3}$ (hydrogen atoms omitted for clarity). Principal bond lengths $[\AA ̊]$ include: $\operatorname{Hg}(1)-\mathrm{C}(1)=2.032(6), \mathrm{Hg}(1)-\mathrm{N}(1)=2.948(6)$, $\mathrm{Hg}(1)-\mathrm{Cl}(1)=2.295(2)$. Principal bond angles $\left[{ }^{\circ}\right]$ include: $\mathrm{N}(1)-$ $\mathrm{Hg}(1)-\mathrm{C}(1)=71.63(2), \mathrm{Cl}(1)-\mathrm{Hg}(1)-\mathrm{C}(1)=178.1(2), \mathrm{Cl}(1)-$ $\mathrm{Hg}(1)-\mathrm{N}(1)=108.23(11)$. Thermal ellipsoids are drawn at the $50 \%$ probability level. Flack parameter $=-0.014(4)$.
Scheme 4. Mercuration of (S)-1 by direct C-H activation.

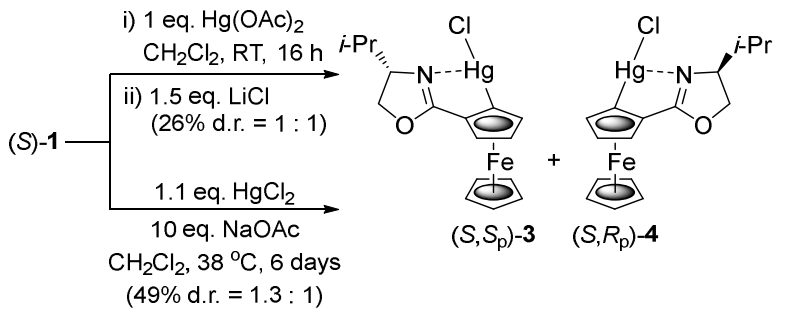

Direct cyclomercuration of $(S)$-1 was investigated with $\mathrm{Hg}(\mathrm{OAc})_{2}$ followed by acetate/chloride ligand exchange, or by the use of $\mathrm{HgCl}_{2}$ in the presence of excess NaOAc (Scheme 4). Both reactions resulted in mercury substituted complexes albeit with no, or very low, diastereoselectivity. Use of cesium pivalate in place of sodium acetate resulted in a 1 : 1 ratio of diastereoisomers. The formation of both diastereoisomers by $\mathrm{C}-\mathrm{H}$ activation was used to confirm, using ${ }^{1} \mathrm{H}$ NMR spectroscopy, the absence of $\left(S, R_{\mathrm{p}}\right)-4$ in the product of the lithiation/transmetallation procedure. For this, the formation of only $\left(S, S_{\mathrm{p}}\right)-\mathbf{3}$ confirms that transmetallation results in no erosion of diastereoselectivity following highly selective lithiation.

Scheme 5. Synthesis of iridacycles by transmetallation of $\left(S, S_{\mathrm{p}}\right)-3$.

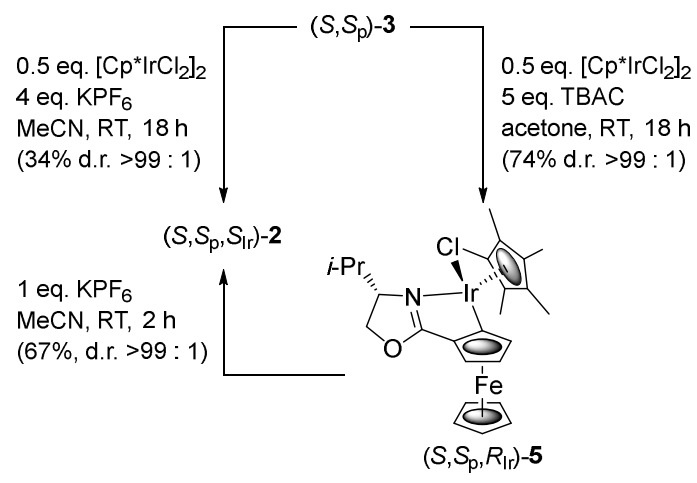

Addition of $\left[\mathrm{Cp}^{*} \mathrm{IrCl}_{2}\right]_{2}$ to $\left(S, S_{\mathrm{p}}\right)-\mathbf{3}$ with either dichloromethane or acetone as solvent resulted only in the recovery of starting material $\left(S, S_{\mathrm{p}}\right)-3$. However, when tetrabutylammonium chloride (TBAC) was included, the reaction in acetone resulted in clean transmetallation (Scheme 5). The broad ${ }^{1} \mathrm{H}$ NMR spectrum of the product matched that of chloride ligated iridacycle $\left(S, S_{\mathrm{p}}, R_{\mathrm{Ir}}\right)-\mathbf{5}$ synthesized previoulsy. ${ }^{7}$ The selectivity of iridacycle formation was determined following addition of $\mathrm{KPF}_{6}$ in acetonitrile and isolation of $\left(S, S_{\mathrm{p}}, S_{\mathrm{Ir}}\right)-2$. No other diastereoisomers were observed in the sharp ${ }^{1} \mathrm{H}$ NMR spectrum obtained from this compound. As ligand substitution reactions in these iridacycles have previously been shown to be stereospecific, proceeding with retention of configuration, this outcome confirms that only a single diastereoisomer of $\left(S, S_{\mathrm{p}}, R_{\mathrm{Ir}}\right)-\mathbf{5}$ was formed on transmetallation. The cationic complex $\left(S, S_{\mathrm{p}}, S_{\mathrm{Ir}}\right)-$ 2 may alternatively be formed, again as a single diastereoisomer, directly by performing the transmetallation reaction in acetonitrile in the presence of $\mathrm{KPF}_{6}$. We also investigated the mercuration of $\left(\eta^{5}-(S)-2-(4-m e t h y l e t h y l) o x a z o l i n y l c y-\right.$ clopentadienyl)( $\eta^{4}$-tetraphenylcyclobutadiene)cobalt (a 
cobalt sandwich complex analogue of $(S)$-1), which gave a 2:1 ratio of $\alpha-\mathrm{HgCl}$ substituted complexes. Mercury to iridium transmetallation was found to proceed in low yield giving a 2:1 ratio of iridacycles (see supporting information).

Scheme 6. Synthesis of $\left(S, R_{\mathrm{p}}\right)-5-d-4$ and subsequent transmetallation to give $\left(S, R_{\mathrm{p}}, S_{\mathrm{Ir}}\right)-5-d-6$ and $\left(S, R_{\mathrm{p}}, R_{\mathrm{Ir}}\right)-5-$ d-7.

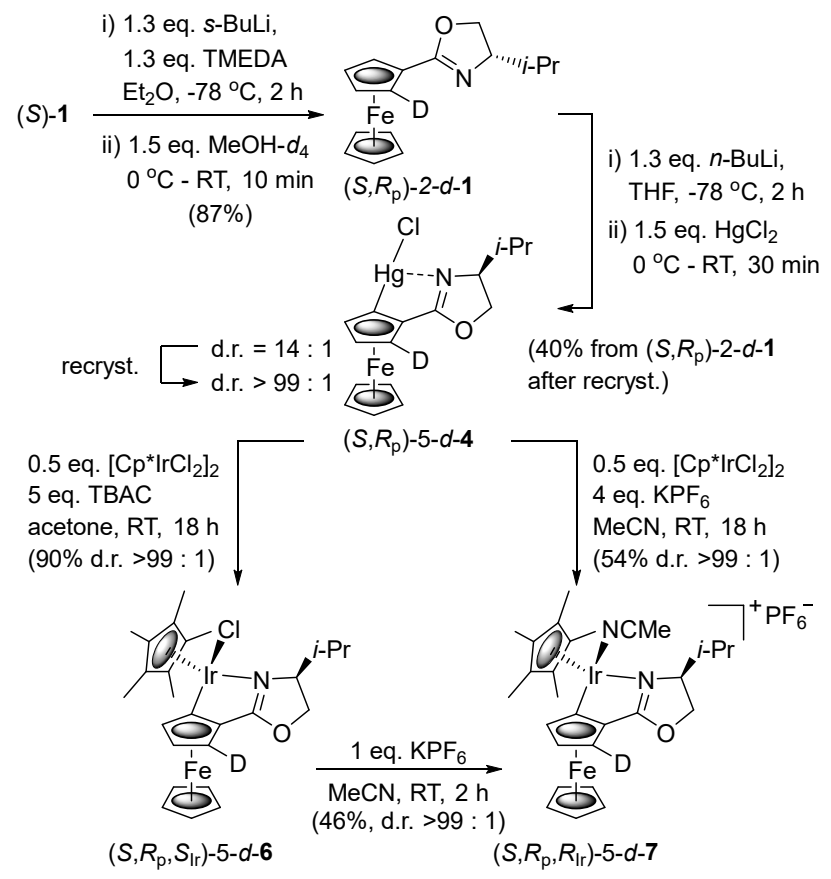

Unlike direct cycloiridation, the lithiation-transmetallation sequence provides $\left(S, S_{\mathrm{p}}, S_{\mathrm{Ir}}\right)-2$ free of small quantities of the planar chiral diastereoisomer $\left(S, R_{\mathrm{p}}, R_{\mathrm{Ir}}\right)-7$, as well as avoiding the formation of iridocenium cations. ${ }^{12}$ We then chose to selectively synthesize this alternative isomer by utilizing a deuterium blocking group to reverse the diastereoselectivity of ferrocenyloxazoline lithiation $\left(k_{\mathrm{H}} / k_{\mathrm{D}} \sim\right.$ 20). ${ }^{13}$ Accordingly, (S)-1 was first lithiated as before followed by the addition of $\mathrm{MeOH}-d_{4}$ to give selectively deuterated $\left(S, R_{\mathrm{p}}\right)-2-d-1$ (Scheme 6). Use of this in a second lithiation reaction with $n$-BuLi in THF, followed by the addition of $\mathrm{HgCl}_{2}$, resulted predominantly in the formation of $\left(S, R_{\mathrm{p}}\right)$ 5-d-4 (d.r. $=10: 1)$. The pure diastereoisomer was obtained readily by recrystallisation, and the identity confirmed by Xray crystallographic analysis (Figure 2). The X-ray structures of both mercury containing complexes reveal an essentially linear coordination about this metal $[\mathrm{C}(1)-\mathrm{Hg}-\mathrm{Cl}=$ $178.1(2)^{\circ}$ in $\left(S, S_{\mathrm{p}}\right)-3$ and $177.1(2)^{\circ}$ in $\left.\left(S, R_{\mathrm{p}}\right)-5-d-4\right]$. In both structures the nitrogen is oriented towards mercury such that the distance between this metal and nitrogen [2.948(6) $\AA$ in $\left(S, S_{\mathrm{p}}\right)-3$ and 2.927(5) $\AA$ in $\left.\left(S, R_{\mathrm{p}}\right)-5-d-4\right]$ is less than the estimated sum of their van der Waals radii $(\sim 3.6 \AA) .{ }^{14}$ As such these complexes are designated as mercuracycles, albeit with a weak and labile $\mathrm{Hg}---\mathrm{N}$ bond as determined for related complexes. ${ }^{14}$ This is supported by the similarity of the oxazoline $\mathrm{C}=\mathrm{N}$ stretch in $(S)-\mathbf{1}$ and $\left(S, S_{\mathrm{p}}\right)-\mathbf{3}(1657$ and $1645 \mathrm{~cm}^{-1}$ respectively).

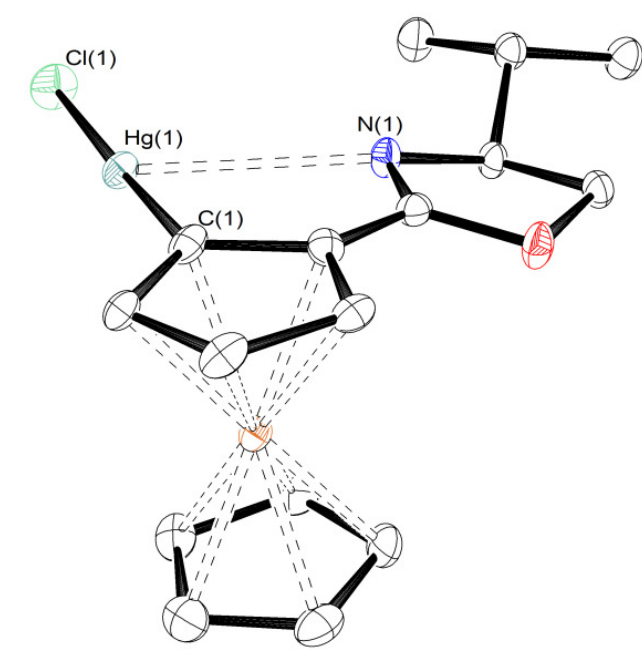

Figure 2. A representation of the X-ray structure of $\left(S, S_{\mathrm{p}}\right)-5-d-$ 4 (hydrogen and deuterium atoms omitted for clarity). Principal bond lengths $[\AA]$ include: $\operatorname{Hg}(1)-C(1)=2.030(6)$, $\mathrm{Hg}(1)-\mathrm{N}(1)=2.927(5), \mathrm{Hg}(1)-\mathrm{Cl}(1)=2.303(2)$. Principal bond angles [ ${ }^{\circ}$ ] include: $\mathrm{N}(1)-\mathrm{Hg}(1)-\mathrm{C}(1)=71.7(2), \mathrm{Cl}(1)-\mathrm{Hg}(1)-\mathrm{C}(1)$ $=177.1(2), \mathrm{Cl}(1)-\mathrm{Hg}(1)-\mathrm{N}(1)=107.88(11)$. Thermal ellipsoids are drawn at the $50 \%$ probability level. Flack parameter $=$ $0.015(4)$.

Transmetallation of $\left(S, R_{\mathrm{p}}\right)-5-d-4$ with $\left[\mathrm{Cp}^{*} \mathrm{IrCl}_{2}\right]_{2}$ in the presence of $\mathrm{KPF}_{6}$ gave iridacycle $\left(S, R_{\mathrm{p}}, R_{\mathrm{Ir}}\right)-5-d-7$ as a single diastereoisomer. The identity of this compound was confirmed by comparison of its ${ }^{1} \mathrm{H}$ NMR spectrum to that of the minor diastereoisomer formed on cycloiridation of $(S)-1{ }^{7}$ The only difference was the absence of a cyclopentadienyl proton signal at $4.85 \mathrm{ppm}$ due to the presence of deuterium. In addition, a NOESY spectrum revealed an NOE between the $\mathrm{Cp}$ and $\mathrm{Cp}^{*}$ moieties in support of the $R_{\mathrm{Ir}}$ configurational assignment. ${ }^{7}$ Transmetallation of $\left(S, R_{\mathrm{p}}\right)-5-d-4$ with $\left[\mathrm{Cp}^{*} \mathrm{IrCl}_{2}\right]_{2}$ in the presence of TBAC gave the neutral chloride ligated complex $\left(S, R_{\mathrm{p}}, S_{\mathrm{Ir}}\right)-5-d-6$. As observed before with chloride ligated iridacycles, the ${ }^{1} \mathrm{H}$ NMR spectrum of this compound was very broad, so its identity and stereochemical integrity were confirmed by conversion into $\left(S, R_{\mathrm{p}}, R_{\mathrm{Ir}}\right)-5-\mathrm{d}-\mathrm{-}$.

Scheme 7. Synthesis of planar chiral Au(I) complex $\left(S, S_{\mathrm{p}}\right)-8$.

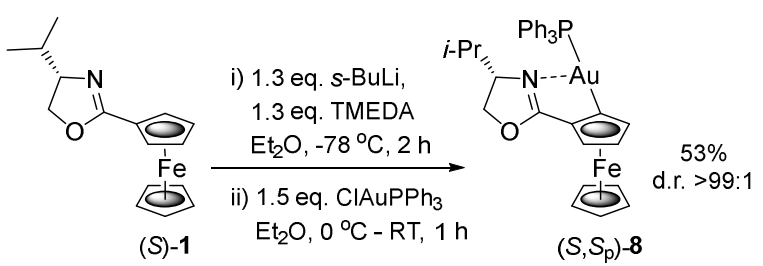

An advantage of using mercuracycles as the transmetallation intermediate in these reactions is the air and water stability of these complexes, such that they may be purified readily to give a single diastereoisomer. A disadvantage is the toxicity of mercury, and this led us to briefly investigate the use of gold as an alternative metal. Accordingly, diastereoselective lithiation of $(S) \mathbf{- 1}$ as before followed by the addition of $\mathrm{ClAuPPh}_{3}$ gave $\left(S, S_{\mathrm{p}}\right)-\mathbf{8}$, the ${ }^{1} \mathrm{H}$ NMR spectrum of 
which displayed three cyclopentadienyl hydrogen signals for the disubstituted ring at 4.89, 4.42 and $4.23 \mathrm{ppm}$, in addition to characteristic signals for a triphenylphosphine ligand. A related synthesis of planar chiral $\mathrm{Au}(\mathrm{I})$ and $\mathrm{Au}(\mathrm{II})$ species derived from ferrocenyloxazoline $(S)-\mathbf{1}$ was reported recently. ${ }^{15}$ Attempted transmetallation with $\left[\mathrm{Cp}^{*} \mathrm{IrCl}_{2}\right]_{2}$ was unsuccessful, and outcome that is likely due to the preference for halogen ligands to be present in both transmetallation partners.

Ugi's amine 9 is the most widely used starting material for the synthesis of planar chiral ferrocene derivatives, ${ }^{16}$ but a previous attempt by us to use this as a substrate for cycloiridation with $\left[\mathrm{Cp}^{*} \mathrm{IrCl}_{2}\right]_{2}$ was unsuccessful. ${ }^{7}$ These reactions led only to the isolation of ferrocene derivatives formed as a result of $\alpha$-substitution, $\alpha$-oxidation or elimination. Transmetallation was therefore investigated as an alternative approach starting with the synthesis of $\left(R, S_{\mathrm{p}}\right)-\mathbf{1 0}$ (Scheme 8). ${ }^{17}$ This was obtained with a small quantity of the alternative $R, R_{\mathrm{p}}$ isomer, and the $10: 1$ ratio of diastereoisomers obtained is similar to the ratio of diastereoisomers resulting initially from lithiation under the conditions used (14: 1). ${ }^{18}$ Transmetallation of $\left(R, S_{\mathrm{p}}\right)-\mathbf{1 0}$ in the presence of excess TBAC proceeded to give a new complex that was purified by recrystallisation. That a new iridacycle had been formed was supported by its ${ }^{1} \mathrm{H}$ NMR spectrum containing three cyclopentadienyl hydrogen signals for the disubstituted ring (4.20, 4.12 and $3.76 \mathrm{ppm}$ ), and a singlet integrating to 15 hydrogens for the $\mathrm{Cp}^{*}$ group at $1.71 \mathrm{ppm}$. Confirmation of the product as $\left(R, S_{\mathrm{p}}, S_{\mathrm{Ir}}\right)-\mathbf{1 1}$ was achieved by an Xray crystallographic analysis (Figure 3).

Scheme 8. Synthesis of iridacycle $\left(R, S_{\mathrm{p}}, S_{\mathrm{Ir}}\right)-11$ via mercurated complex $\left(R, S_{\mathrm{p}}\right)-10$.

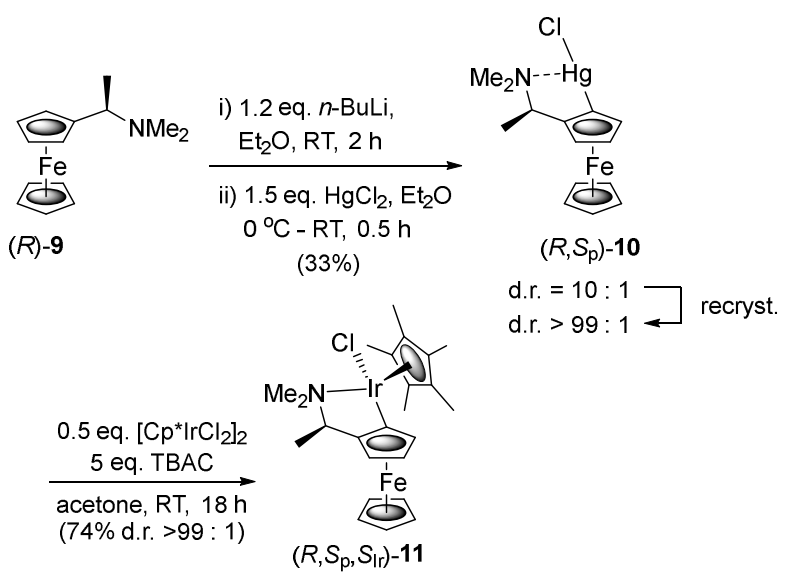

The relative configuration of the planar and iridium-centred elements of chirality in $\left(R, S_{\mathrm{p}}, S_{\mathrm{Ir}}\right)-\mathbf{1 1}$ is different to that observed previously in related imine and oxazoline containing ferrocene and cobalt-sandwich based complexes obtained by cycloiridation. ${ }^{7.8}$ The chloride ligand of $\left(R, S_{\mathrm{p}}, S_{\mathrm{Ir}}\right)-$ $\mathbf{1 1}$ is oriented towards rather than away from iron, changing the configuration of the pseudo-tetrahedral stereogenic center. A previous study on imine containing iridacycles similar to 5 revealed little difference in energy between the $\left(S_{\mathrm{p}}{ }^{*}, R_{\mathrm{Ir}}{ }^{*}\right)$ and $\left(S_{\mathrm{p}}{ }^{*}, S_{\mathrm{Ir}}{ }^{*}\right)$-configured diastereoisomers. ${ }^{7}$ The selective formation of the former on cycloiridation was ascribed to a stereoelectronic effect dictating facile dissociative ligand substitution along a trajectory opposite to iron, such that base assisted concerted metallation deprotonation followed by introduction of a chloride ligand by substitution, resulted in the relative configuration $S_{\mathrm{p}}{ }^{*}, R_{\mathrm{Ir}}{ }^{*}$. As discussed above, transmetallation of lithiated ferrocenyloxazolines with $\left[\mathrm{Cp}^{*} \mathrm{IrCl}_{2}\right]_{2}$ results in the same outcome.

There are a number of ruthenium, iridium and rhodium half-sandwich $\mathrm{Cp}^{*}$-containing metallacycles derived from $\alpha$-methylbenzylamine, and related derivatives, that have been synthesized using a variety of procedures. ${ }^{19}$ In almost all of these the cyclopentadienyl moiety is exclusively or predominantly syn to the $\alpha$-methyl group such that this would appear to be the kinetically and thermodynamically preferred epimer. ${ }^{20}$ Iridacycle $\left(R, S_{\mathrm{p}}, S_{\mathrm{Ir}}\right)-\mathbf{1 1}$ also displays this syn relationship. All attempts at ligand substitution with $\left(R, S_{\mathrm{p}}, S_{\mathrm{Ir}}\right)-\mathbf{1 1}$, for example by treating this complex with $\mathrm{KPF}_{6}$ in $\mathrm{MeCN}$, were unsuccessful and resulted in decomposition. This outcome is compatible with our previous inability to synthesize this complex by base promoted cycloiridation. ${ }^{7}$ That transmetallation is successful is a result of this procedure not requiring the formation of a coordinatively unsaturated, and in this case unstable, intermediate complex. In light of this successful transmetallation we sought to extend this chemistry following modification of the dimethylamino group of $\left(R, S_{\mathrm{p}}\right)$-10. However, all attempts to replace this with a methylamino group by $\alpha$-substitution were unsuccessful (see supporting information).

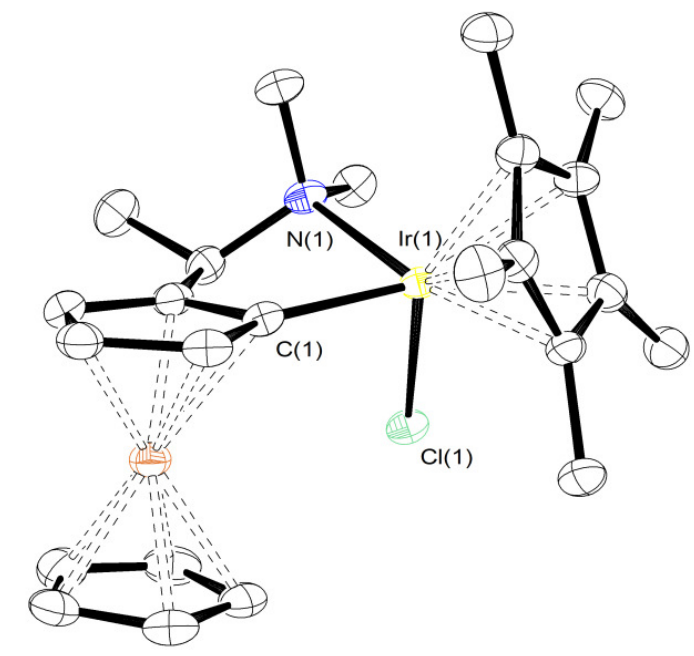

Figure 3. A representation of the X-ray structure of $\left(R, S_{\mathrm{p}}, S_{\mathrm{Ir}}\right)$ 11 (hydrogen atoms omitted for clarity). Principal bond lengths $[\AA]$ include: $\operatorname{Ir}(1)-\mathrm{C}(1)=2.039(4), \operatorname{Ir}(1)-\mathrm{N}(1)=$ $2.220(3), \operatorname{Ir}(1)-\mathrm{Cl}(1)=2.4257(10), \operatorname{Ir}(1)-\mathrm{Cp}^{*}$ (centre of mass $)=$ 1.822. Principal bond angles [ $\left.{ }^{\circ}\right]$ include: $\mathrm{N}(1)-\operatorname{Ir}(1)-\mathrm{C}(1)=$ 76.90(17), $\mathrm{Cl}(1)-\operatorname{Ir}(1)-\mathrm{C}(1)=93.42(13), \mathrm{Cl}(1)-\operatorname{Ir}(1)-\mathrm{N}(1)=$ 85.82(14), N(1)-Ir(1)-Cp* ${ }^{*} 134.05, \mathrm{C}(1)-\operatorname{Ir}(1)-\mathrm{Cp}^{*}=132.06$. Thermal ellipsoids are drawn at the $50 \%$ probability level. Flack parameter $=-0.024(4)$. 
Scheme 9. Synthesis of cobalt sandwich complex based mercury derivative $\left(R, S_{\mathrm{p}}\right)-13$.

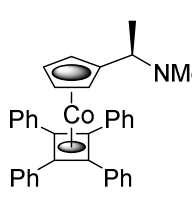

$(R)-12$

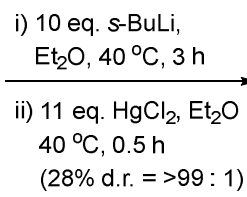

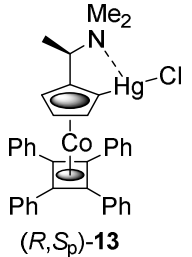

In an attempt to extend this methodology we also investigated the lithiation and subsequent transmetallation of $(R)$ 12, a bulky cobalt sandwich complex analogue of Ugi's amine (Scheme 9). ${ }^{18}$ As was found with its ferrocene-based equivalent, $(R)$-12 underwent $\alpha$-substitution, $\alpha$-oxidation or elimination on attempted direct cycloiridation (see supporting information). Thus, following highly diastereoselective lithiation of $(R)-12$ (>99: 1), ${ }^{18}$ addition of excess $\mathrm{HgCl}_{2}$ led to the isolation by chromatography of $\left(R, S_{\mathrm{p}}\right)-\mathbf{1 3}$ together with recovered $(R)-\mathbf{1 2}$. The ${ }^{1} \mathrm{H}$ NMR spectrum of the new compound displayed a single set of three characteristic cyclopentadienyl hydrogen signals at 4.79, 4.64 and $4.27 \mathrm{ppm}$. Attempted transmetallation of $\left(R, S_{\mathrm{p}}\right) \mathbf{- 1 3}$ with $\left[\mathrm{Cp}^{*} \mathrm{IrCl}_{2}\right]_{2}$, under the room temperature conditions used previously, or on heating at reflux, was unsuccessful and resulted only in the recovery of starting material $\left(R, S_{\mathrm{p}}\right)$-13. The low reactivity of bulky cobalt-based sandwich complexes in related metallation reactions has been noted previously. ${ }^{21}$

Scheme 10. Iridacycle catalysed reductive amination.

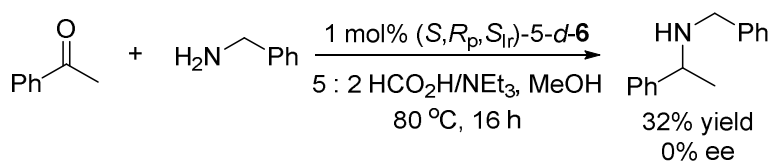

In light of the extensive application of half-sandwich iridacycles derived from ketimines as catalysts for transfer hydrogenation, ${ }^{22}$ it was anticipated that the ferrocenyloxazoline derived iridacycles of this study could also be applied to such reactions. In a preliminary investigation, a mixture of acetophenone and benzylamine underwent reductive amination when heated with an azeotropic mixture of formic acid and triethylamine in the presence of $1 \mathrm{~mol} \%$ $\left(S, R_{\mathrm{p}}, S_{\text {Ir }}\right)-5-d-6$ (Scheme 10$)$. Following acetylation (see supporting information), the product of this reaction was determined by chiral HPLC to be racemic. On the basis of an experimental and computational study, the mechanism of intermediate imine reduction is proposed to proceed by rate determining iridacycle hydride formation followed by outer-sphere hydride transfer to the imino bond. ${ }^{23}$ In light of this, it is notable that the use of a related chiral non-racemic iridacycle as a catalyst for reductive amination resulted in a complete absence of stereoinduction. ${ }^{24}$

\section{CONCLUSION}

Transmetallation is a viable alternative to cycloiridation as a method for the synthesis of ferrocene-based planar chiral iridacycles. Although lithium to iridium transmetallation did not prove possible, lithium to mercury followed by mercury to iridium transmetallation reactions were successful. This process provided access to iridacycles that were previously unavailable by direct introduction of iridium by $\mathrm{C}-\mathrm{H}$ activation. In the first example, the reversal of ferrocenyloxazoline lithiation diastereoselectivity by use of a deuterium blocking group led to the exclusive synthesis of the minor diastereoisomer generated previously by cycloiridation. In the second example, the transmetallation approach gave access to an iridacycle derived from Ugi's amine; whereas previously attempted cycloiridation had resulted in substrate degradation. The intermediate mercuracycles generated in this study are air and water stable, and may be purified to remove any minor diastereoisomer arising from incomplete selectivity on substrate lithiation. Gold was investigated as an alternative to mercury, transmetallation providing access to a planar chiral Au(I) species. A preliminary investigation into the use of an enantiomerically and diastereomerically pure iridacycle as a catalyst for reductive amination resulted in the formation of a racemic product.

\section{EXPERIMENTAL SECTION}

General remarks. Caution! All organomercurials are highly toxic. Extreme care is necessary when handling all products and their solutions. Diethyl ether and THF were distilled over sodium and benzophenone ketyl. Acetonitrile and dichloromethane were dried by distillation from calcium hydride. Methanol was dried over 4 Å molecular sieves. All cycloiridation reactions and reactions involving the use of dry solvents were carried out under an inert atmosphere of either nitrogen or argon. Silica gel (60 ̊̊ pore size, 40 - $63 \mu \mathrm{m}$ technical grade) and neutral aluminum oxide (Brockmann I, 50 $200 \mu \mathrm{m})$ were used for chromatography.

Synthesis of $\left(\boldsymbol{S}, \boldsymbol{S}_{\mathrm{p}}\right)-\mathbf{3}$. $(S)-\mathbf{1}^{25}(0.15 \mathrm{~g}, 0.51 \mathrm{mmol})$ was added to a flame dried Schlenk tube under an atmosphere of argon and dissolved in dry diethyl ether $(6 \mathrm{~mL})$. TMEDA $(0.10 \mathrm{~mL}, 0.66 \mathrm{mmol})$ was added and the subsequent orange solution was cooled to -78 ${ }^{\circ} \mathrm{C}$ and stirred for 5 minutes after which sec-butyllithium (1.4 M in hexanes) ( $0.47 \mathrm{~mL}, 0.66 \mathrm{mmol})$ was added slowly. In a separate Schlenk tube mercury(II) chloride $(0.2741 \mathrm{~g}, 1.01 \mathrm{mmol})$ was dried by heating under high vacuum and allowed to cool. After the reaction had stirred for 2 hours the mixture was warmed to $0^{\circ} \mathrm{C}$ and a partial suspension of mercury(II) chloride was added (using dry diethyl ether $(6 \mathrm{~mL})$ ) to the reaction mixture and stirred for 10 minutes. The reaction was allowed to warm to room temperature, and after an additional 30 minutes, was quenched with saturated sodium hydrogen carbonate solution. The organics were separated with $\mathrm{H}_{2} \mathrm{O}$, washed with brine, dried over $\mathrm{MgSO}_{4}$ and upon removal of the solvent in vacuo gave a crude product. Column chromatography $\left(\mathrm{SiO}_{2}, 10 \% \mathrm{EtOAc} /\right.$ hexane) yielded a yellow solid as a single diastereoisomer $(0.1748 \mathrm{~g}, 65 \%) . R_{\mathrm{f}} 0.51$ (10 \% EtOAc in hexane). Mp: $149-152{ }^{\circ} \mathrm{C} .[\alpha]_{D} 22.5^{\circ} \mathrm{C}=-312\left(c 0.2, \mathrm{CHCl}_{3}\right)$. IR (film): 3093 , 2957, 2924, 2869, 1645 (CN). ${ }^{1} \mathrm{H}$ NMR $\left(500 \mathrm{MHz}, \mathrm{CDCl}_{3}\right): 4.84(1 \mathrm{H}$, $\left.\mathrm{dd}, 3_{\mathrm{HH}}=2.6,{ }^{4} J_{\mathrm{HH}}=1.1 \mathrm{~Hz}, \mathrm{CpH}\right), 4.52\left(1 \mathrm{H}, \mathrm{apt}, 3+3 \int_{\mathrm{HH}}=2.4 \mathrm{~Hz}, \mathrm{CpH}\right)$, $4.45\left(1 \mathrm{H}, \mathrm{dd},{ }^{2} J_{\mathrm{HH}}=9.6,{ }^{3} J_{\mathrm{HH}}=8.4 \mathrm{~Hz}, \mathrm{CHH}\right), 4.31\left(1 \mathrm{H}, \mathrm{dd},{ }^{3} J_{\mathrm{HH}}=2.4\right.$, $\left.{ }^{4} J_{\mathrm{HH}}=1.1 \mathrm{~Hz}, \mathrm{Cp} H\right), 4.21(5 \mathrm{H}, \mathrm{s}, \mathrm{CpH}), 4.14\left(1 \mathrm{H}, \mathrm{apt},{ }^{2+3} \mathrm{JHH}_{\mathrm{HH}}=8.2 \mathrm{~Hz}\right.$, $\mathrm{CH} H), 3.90-3.85(1 \mathrm{H}, \mathrm{m}, \mathrm{CH}), 1.76-1.71(1 \mathrm{H}, \mathrm{m}, \mathrm{CH}), 1.06(3 \mathrm{H}, \mathrm{d}$, $\left.{ }^{3} \mathrm{JHH}_{\mathrm{HH}}=6.7 \mathrm{~Hz}, \mathrm{CH}_{3}\right), 1.02\left(3 \mathrm{H}, \mathrm{d},{ }^{3} \mathrm{JHH}_{\mathrm{HH}}=6.7 \mathrm{~Hz}, \mathrm{CH}_{3}\right) .{ }^{13} \mathrm{C} \mathrm{NMR}(125$ $\left.\mathrm{MHz}, \mathrm{CDCl}_{3}\right): 168.6(C=\mathrm{N}), 85.8(\mathrm{CpCC}), 75.5(\mathrm{CpCH}), 74.5(\mathrm{CpCHg})$, $73.0(\mathrm{CpCH}), 72.0\left(\mathrm{CH}_{2}\right), 71.8(\mathrm{CH}), 70.2\left(\mathrm{C}_{5} \mathrm{H}_{5}\right), 70.1(\mathrm{CpCH}), 33.0$ $(\mathrm{CH}), 19.2\left(\mathrm{CH}_{3}\right), 18.8\left(\mathrm{CH}_{3}\right)$. High resolution MS $\left(\mathrm{m} / \mathrm{z}, \mathrm{APCI}+{ }^{+}\right.$: 
found for $[\mathrm{M}+\mathrm{H}]^{+}=534.0189$, calcd for $\mathrm{C}_{16} \mathrm{H}_{18} \mathrm{ClFeHgNO}+\mathrm{H}^{+}$ 534.0199 .

Synthesis of $\left(\boldsymbol{S}, \boldsymbol{S}_{\mathrm{p}}, \boldsymbol{R}_{\mathrm{Ir}}\right)-\mathbf{5}$. $\left(S, S_{\mathrm{p}}\right)-\mathbf{3}(0.033 \mathrm{~g}, 0.06 \mathrm{mmol})$, (pentamethylcyclopentadienyl)iridium(III) chloride dimer $(0.025 \mathrm{~g}, 0.03$ $\mathrm{mmol})$ and tetrabutylammonium chloride $(0.087 \mathrm{~g}, 0.31 \mathrm{mmol})$ were added to a flame dried Schlenk tube under an inert atmosphere. Acetone $(2 \mathrm{~mL})$ was added and the resulting red solution was allowed to stir at room temperature overnight. The reaction mixture was filtered through Celite ${ }^{\mathrm{TM}}$ using dichloromethane as the eluent and the solvent removed in vacuo. Excess tetrabutylammonium chloride was removed by re-dissolving the orange residue in hexane and separating with brine $(4 \times 50 \mathrm{~mL})$. The organics were dried by filtering through a glass wool pad loaded with magnesium sulfate and removing the solvent in vacuo to give a tacky orange solid $(0.03 \mathrm{~g}, 74 \%)$. Data as previously reported. ${ }^{7}$

Synthesis of $\left(\boldsymbol{S}, \boldsymbol{S}_{\mathrm{p}}, \boldsymbol{S}_{\mathrm{Ir}}\right)-\mathbf{2}$. $\left(S, S_{\mathrm{p}}\right)-3(0.033 \mathrm{~g}, 0.06 \mathrm{mmol})$, (pentamethylcyclopentadienyl)iridium(III) chloride dimer $(0.025 \mathrm{~g}, 0.03$ $\mathrm{mmol})$ and potassium hexafluorophosphate $(0.047 \mathrm{~g}, 0.25 \mathrm{mmol})$ were added to a flame dried Schlenk tube under an inert atmosphere. Acetonitrile $(3 \mathrm{~mL})$ was added and the resulting red solution was allowed to stir at room temperature overnight. The reaction mixture was washed with hexane until the hexane layer became colorless. The solvent from the acetonitrile layer was reduced in vacuo. Purification was achieved by filtering through a $30 \mathrm{~cm}$ pad of neutral alumina, using acetonitrile as the eluent, and collecting the first bright orange fractions (subsequent pale yellow fractions contained starting material and decomposition products). Removal of the solvent in vacuo yielded the desired product as an amorphous air sensitive orange solid (0.02 g, $34 \%)$. Data as previously reported. ${ }^{7}$

Synthesis of $\left(\boldsymbol{S}, \boldsymbol{R}_{\mathrm{p}}\right)-\mathbf{5}-\mathbf{d}-\mathbf{4} .(S)-2-d-\mathbf{1}^{13}(0.260 \mathrm{~g}, 0.87 \mathrm{mmol})$ was added to a flame dried Schlenk tube under an atmosphere of argon and dissolved in dry tetrahydrofuran $(2 \mathrm{~mL})$. The subsequent orange solution was cooled to $-78^{\circ} \mathrm{C}$ and stirred for 5 minutes after which $n$-butyllithium (2.5 M in hexanes) ( $0.45 \mathrm{~mL}, 1.13 \mathrm{mmol}$ ) was added slowly. In a separate Schlenk tube mercury(II) chloride $(0.355 \mathrm{~g}, 1.32 \mathrm{mmol})$ was dried by heating under high vacuum and allowed to cool. After the reaction had stirred for 2 hours the mixture was warmed to $0{ }^{\circ} \mathrm{C}$ and a partial suspension of mercury(II) chloride was added (using dry THF $(2 \mathrm{~mL})$ ) to the reaction mixture and stirred for 10 minutes. The reaction was allowed to warm to room temperature, and after an additional 20 minutes was diluted with diethyl ether and then quenched with saturated sodium hydrogen carbonate. The organics were separated with water, washed with brine, dried over magnesium sulfate and upon removal of the solvent in vacuo gave a crude product (14:1 mixture of diastereoisomers). Column chromatography $\left(\mathrm{SiO}_{2}, 10 \%\right.$ EtOAc/hexane) yielded an orange solid that was recrystallized from diethyl ether and hexane giving the product a single diastereoisomer (0.206 g, $44 \%, 99 \%$ D-incorp.). $R_{\mathrm{f}} 0.54 \quad(20 \%$ EtOAc/hexane). Mp: $129^{\circ} \mathrm{C} .[\alpha]_{D^{22.5} 5^{\circ} \mathrm{C}}=+222\left(c\right.$ 0.9, $\left.\mathrm{CHCl}_{3}\right)$. IR (film): 3090, 2958, 2898, 2871, 1640 (CN). ${ }^{1} \mathrm{H}$ NMR (500 MHz, $\left.\mathrm{CDCl}_{3}\right): 4.53(1 \mathrm{H}, \mathrm{brs}, \mathrm{CpH}), 4.46\left(1 \mathrm{H}, \mathrm{apt},{ }^{2+3} \mathrm{HHH}_{\mathrm{HH}}=8.6 \mathrm{~Hz}, \mathrm{CHH}\right), 4.30$ $(1 \mathrm{H}, \mathrm{brs}, \mathrm{CpH}), 4.22(5 \mathrm{H}, \mathrm{s}, \mathrm{CpH}), 4.03\left(1 \mathrm{H}, \mathrm{apt},{ }^{2+3} \int_{\mathrm{HH}}=7.7 \mathrm{~Hz}, \mathrm{CH} H\right)$, $3.91-3.81(1 \mathrm{H}, \mathrm{m}, \mathrm{CH}), 1.71-1.62(1 \mathrm{H}, \mathrm{m}, \mathrm{CH}), 1.01\left(3 \mathrm{H}, \mathrm{d}, 3 \mathrm{~J}_{\mathrm{HH}}=\right.$ $\left.6.5 \mathrm{~Hz}, \mathrm{CH}_{3}\right), 0.92\left(3 \mathrm{H}, \mathrm{d},{ }^{3} \mathrm{JHH}_{\mathrm{HH}}=6.5 \mathrm{~Hz}, \mathrm{CH}_{3}\right) .{ }^{13} \mathrm{C} \mathrm{NMR}(125 \mathrm{MHz}$, $\left.\mathrm{CDCl}_{3}\right): 168.5(C=\mathrm{N}), 86.4(\mathrm{Cp} C \mathrm{C}), 75.5(\mathrm{CpC}), 74.2(\mathrm{CpCHg}), 72.9$ $(\mathrm{CpCH}), 72.3\left(\mathrm{CH}_{2} \& \mathrm{CH}\right), 70.2\left(\mathrm{C}_{5} \mathrm{H}_{5}\right), 33.3(\mathrm{CH}), 19.1\left(2 \mathrm{CH}_{3}\right)$. High resolution $\mathrm{MS}\left(\mathrm{m} / \mathrm{z}, \mathrm{ASAP}^{+}\right)$: found for $[\mathrm{M}+\mathrm{H}]^{+}=535.0276$, calcd for $\mathrm{C}_{16} \mathrm{H}_{17} \mathrm{DClFeHgNO}+\mathrm{H}^{+} 535.0267$

Synthesis of $\left(\boldsymbol{S}, \boldsymbol{R}_{\mathrm{p}}, \boldsymbol{S}_{\mathrm{Ir}}\right)-\mathbf{5}-\boldsymbol{d}-\mathbf{6}$. $\left(S, R_{\mathrm{p}}\right)-5-d-4(0.0425 \mathrm{~g}, 0.085 \mathrm{mmol})$, (pentamethylcyclopentadienyl)iridium(III) chloride dimer $(0.0336 \mathrm{~g}, 0.042 \mathrm{mmol})$ and tetrabutylammonium chloride $(0.1174$ g, $0.422 \mathrm{mmol}$ ) were added to a flame dried Schlenk tube under an inert atmosphere. Acetone $(3 \mathrm{~mL})$ was added and the resulting red solution was allowed to stir at room temperature overnight. The reaction mixture was filtered through Celite $^{T M}$ using dichloromethane as the eluent and the solvent removed in vacuo. Excess tetrabutylammonium chloride was removed by re-dissolving the orange residue in hexane (a small amount of acetone was added to aid dissolution) and separating with brine $(4 \times 50 \mathrm{~mL})$. The organics were dried by filtering through a glass wool pad loaded with magnesium sulfate and removing the solvent in vacuo to give an

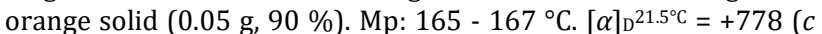
$0.20, \mathrm{CHCl}_{3}$ ). IR (film): 2953, 2923, 2853, 1607. High resolution MS $\left(\mathrm{m} / \mathrm{z}, \mathrm{NSI}^{+}\right)$: found for $[\mathrm{M}-\mathrm{Cl}]^{+}=625.1599$, calcd for $\mathrm{C}_{26} \mathrm{H}_{32} \mathrm{FeIrNO}^{+}$ 625.1599 .

Synthesis of $\left(\boldsymbol{S}, \boldsymbol{R}_{\mathrm{p}}, \boldsymbol{R}_{\mathrm{Ir}}\right)-\mathbf{5}-\boldsymbol{d}-7 .\left(S, R_{\mathrm{p}}\right)-5-d-4(0.034 \mathrm{~g}, 0.06 \mathrm{mmol})$, (pentamethylcyclopentadienyl)iridium(III) chloride dimer $(0.025$ $\mathrm{g}, 0.03 \mathrm{mmol})$ and potassium hexafluorophosphate $(0.047 \mathrm{~g}, 0.25$ $\mathrm{mmol}$ ) were added to a flame dried Schlenk tube under an inert atmosphere. Acetonitrile $(5 \mathrm{~mL})$ was added and the resulting red solution was allowed to stir at room temperature overnight. The reaction mixture was separated with hexane until the hexane layer became colorless. The acetonitrile layer was reduced in vacuo. $\mathrm{Pu}-$ rification was achieved by filtering through a $30 \mathrm{~cm}$ pad of neutral alumina, using acetonitrile as the eluent, and collecting the first bright orange fractions. Removal of the solvent in vacuo yielded the desired product as an amorphous air sensitive orange solid $(0.028$ g, $54 \%) \cdot[\alpha]_{\mathrm{D}} 25.7^{\circ} \mathrm{C}=+665(c 1.89, \mathrm{MeCN}) .{ }^{1} \mathrm{H}$ NMR $(500 \mathrm{MHz}, \mathrm{MeCN}-$ $\left.\mathrm{d}^{3}\right): 4.82-4.75(2 \mathrm{H}, \mathrm{m}, \mathrm{CHH}+\mathrm{CH} H), 4.54\left(1 \mathrm{H}, \mathrm{d},{ }^{3} J_{\mathrm{HH}}=1.5 \mathrm{~Hz}, \mathrm{CpH}\right)$, $4.46\left(1 \mathrm{H}, \mathrm{d},{ }^{3} \mathrm{HHH}_{\mathrm{HH}}=2.0 \mathrm{~Hz}, \mathrm{CpH}\right), 4.12(5 \mathrm{H}, \mathrm{s}, \mathrm{CpH}), 4.10(1 \mathrm{H}, \mathrm{ddd}$, $\left.{ }^{3} \mathrm{JHH}_{\mathrm{HH}}=8.9,{ }^{3} \mathrm{HH}_{\mathrm{HH}}=4.9,{ }^{3} \mathrm{HH}_{\mathrm{HH}}=2.4 \mathrm{~Hz}, \mathrm{CH}\right), 1.91\left(15 \mathrm{H}, \mathrm{s}, \mathrm{C}_{5}\left(\mathrm{CH}_{3}\right)_{5}\right), 1.89$ - $1.87(1 \mathrm{H}, \mathrm{m}, \mathrm{CH}), 0.98\left(3 \mathrm{H}, \mathrm{d},{ }^{3} \mathrm{~J}_{\mathrm{HH}}=7.2 \mathrm{~Hz}, \mathrm{CH}_{3}\right), 0.68\left(3 \mathrm{H}, \mathrm{d},{ }^{3}{ }_{\mathrm{HH}}\right.$ $\left.=6.7 \mathrm{~Hz}, \mathrm{CH}_{3}\right) .{ }^{13} \mathrm{C}$ NMR (125 MHz, MeCN-d $\left.\mathrm{d}^{3}\right): 183.7(\mathrm{C}=\mathrm{N}), 91.4$ $\left(\mathrm{C}_{5}\left(\mathrm{CH}_{3}\right)_{5}\right), 90.4(\mathrm{CpClr}), 74.4(\mathrm{CpCC}), 74.0(\mathrm{CpCH}), 73.7\left(\mathrm{CH}_{2}\right), 72.6$ $(\mathrm{CpCH}), 70.7\left(\mathrm{C}_{5} \mathrm{H}_{5}\right), 67.5(\mathrm{CH}), 65.9(\mathrm{CpCD}), 30.1(\mathrm{CH}), 19.3\left(\mathrm{CH}_{3}\right)^{\prime}$, $14.5\left(\mathrm{CH}_{3}\right), 9.9\left(\mathrm{C}_{5}\left(\mathrm{CH}_{3}\right)_{5}\right)$. High resolution MS $\left(\mathrm{m} / \mathrm{z}, \mathrm{NSI}^{+}\right)$: found for $\left[\mathrm{M}-\left(\mathrm{PF}_{6}+\mathrm{MeCN}\right)\right]^{+}=625.1586$, calcd for $\mathrm{C}_{26} \mathrm{H}_{32} \mathrm{DFeIrNO}^{+}$ 625.1599.

Conversion of $\left(S, R_{\mathrm{p}}, S_{\mathrm{Ir}}\right)-\mathbf{5}-\boldsymbol{d}-\mathbf{6}$ into $\left(\boldsymbol{S}, \boldsymbol{R}_{\mathrm{p}}, \boldsymbol{R}_{\mathrm{Ir}}\right)-5-\boldsymbol{d}-7$. $\left(S, R_{\mathrm{p}}, S_{\mathrm{Ir}}\right)-5$-d $6(0.0170 \mathrm{~g}, 0.026 \mathrm{mmol})$ and potassium hexafluorophosphate $(0.0048 \mathrm{~g}, 0.026 \mathrm{mmol})$ were added to a flame dried Schlenk tube under an inert atmosphere. After dissolving in dry acetonitrile the reaction mixture was stirred for $2 \mathrm{~h}$ at room temperature. The reaction mixture was washed with hexane until the hexane layer became colorless. The acetonitrile layer was reduced in vacuo. Purification was achieved by filtering through a $30 \mathrm{~cm}$ pad of neutral alumina, using acetonitrile as the eluent, and collecting the first bright orange fractions. Removal of the solvent in vacuo yielded the desired product as an amorphous air sensitive orange solid $(0.01 \mathrm{~g}$, $46 \%)$.

Synthesis of $\left(\boldsymbol{S}, \boldsymbol{S}_{\mathrm{p}}\right)-\mathbf{8}$. $(S)-\mathbf{1}^{25}(0.100 \mathrm{~g}, 0.34 \mathrm{mmol})$ was added to a flame dried Schlenk tube under an atmosphere of argon and dissolved in dry diethyl ether $(5 \mathrm{~mL})$. TMEDA $(0.070 \mathrm{~mL}, 0.44 \mathrm{mmol})$ was added and the subsequent orange solution was cooled to -78 ${ }^{\circ} \mathrm{C}$ and stirred for 5 minutes after which sec-butyllithium (1.4 M in hexanes) $(0.310 \mathrm{~mL}, 0.44 \mathrm{mmol})$ was added slowly. After stirring for $2 \mathrm{~h}$ the mixture was warmed to $0{ }^{\circ} \mathrm{C}$ and a suspension of chloro(triphenylphosphine)gold(I) $(0.250 \mathrm{~g}, 0.51 \mathrm{mmol})$ in dry diethyl ether $(10 \mathrm{~mL})$ was added via syringe and the resulting mixture stirred vigorously for 1 hour at room temperature. The reaction was quenched with saturated sodium hydrogen carbonate solution, washed with water, dried over magnesium sulfate followed by removal of the solvent in vacuo to give an orange residue. This was taken up in hexane and filtered through a glass frit leaving a white solid behind. The orange filtrate was concentrated and a recrystallisation performed from boiling hexane, followed by washing with ice cooled hexane, to yield an orange solid as a single dia-

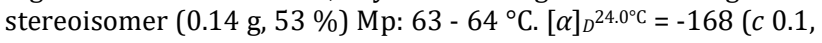
$\mathrm{CHCl}_{3}$ ). IR (film): 3067, 2958, 2892, 1642 (CN). ${ }^{1} \mathrm{H}$ NMR $(500 \mathrm{MHz}$, $\left.\mathrm{CDCl}_{3}\right): 7.72$ - $7.67\left(6 \mathrm{H}, \mathrm{m}, \mathrm{PPh}_{3}\right), 7.49-7.46\left(9 \mathrm{H}, \mathrm{m}, \mathrm{PPh}_{3}\right), 4.90-$ $4.88(1 \mathrm{H}, \mathrm{m}, \mathrm{Cp} H), 4.44-4.41(1 \mathrm{H}, \mathrm{m}, \mathrm{Cp} H), 4.25-4.20(2 \mathrm{H}, \mathrm{m}, \mathrm{Cp} H$ $+\mathrm{CHH}), 4.16(5 \mathrm{H}, \mathrm{s}, \mathrm{CpH}), 4.01\left(1 \mathrm{H}, \mathrm{apt},{ }^{2+3}{ }_{\mathrm{HH}}=7.5 \mathrm{~Hz}, \mathrm{CH} H\right), 3.97$ $-3.92(1 \mathrm{H}, \mathrm{m}, \mathrm{CH}), 1.81-1.64(1 \mathrm{H}, \mathrm{m}, \mathrm{CH}), 0.87\left(3 \mathrm{H}, \mathrm{d},{ }^{3} \mathrm{HH}_{\mathrm{HH}}=6.8 \mathrm{~Hz}\right.$, $\left.\mathrm{CH}_{3}\right), 0.80\left(3 \mathrm{H}, \mathrm{d},{ }^{3} \mathrm{~J}_{\mathrm{HH}}=6.8 \mathrm{~Hz}, \mathrm{CH}_{3}\right) .{ }^{13} \mathrm{C}$ NMR $\left(125 \mathrm{MHz}, \mathrm{CDCl}_{3}\right)$ : $169.0(C=\mathrm{N}), 134.6\left(\mathrm{~d},{ }^{2} J_{\mathrm{CP}}=13.9 \mathrm{~Hz}, \mathrm{ArC}\right), 131.7\left(\mathrm{~d},{ }^{1} J_{\mathrm{HH}}=50.0 \mathrm{~Hz}\right.$, $\mathrm{ArC}), 131.1\left(\mathrm{~d},{ }^{4} J_{\mathrm{CP}}=2.0 \mathrm{~Hz}, \operatorname{Ar} C\right), 129.0\left(\mathrm{~d},{ }^{3} \mathrm{JP}_{\mathrm{CP}}=10.7 \mathrm{~Hz}, \operatorname{ArC}\right)$, 
$103.2\left(\mathrm{~d},{ }^{2} J_{\mathrm{CP}}=122.6 \mathrm{~Hz}, \mathrm{CpCAu}\right), 79.4\left(\mathrm{~d},{ }^{4} J_{\mathrm{CP}}=4.1 \mathrm{~Hz}, \mathrm{CpCH}\right), 77.8$ $\left(\mathrm{d},{ }^{3} J_{\mathrm{CP}}=4.6 \mathrm{~Hz}, \mathrm{CpCC}\right), 72.4(\mathrm{CH}), 72.1\left(\mathrm{~d},{ }^{4} J_{\mathrm{CP}}=5.8 \mathrm{~Hz}, \mathrm{CpCH}\right), 71.0$ (d, $\left.{ }^{3}{ }_{\mathrm{CP}}=5.1 \mathrm{~Hz}, \mathrm{CpCH}\right), 69.0\left(\mathrm{CH}_{2}\right), 68.9\left(\mathrm{C}_{5} \mathrm{H}_{5}\right), 32.5(\mathrm{CH}), 19.2$ $\left(\mathrm{CH}_{3}\right), 17.9\left(\mathrm{CH}_{3}\right) .{ }^{31} \mathrm{P}$ NMR $\left(202 \mathrm{MHz}, \mathrm{CDCl}_{3}\right)$ : $44.06\left(\mathrm{PPh}_{3}\right)$. High resolution $\mathrm{MS}\left(\mathrm{m} / \mathrm{z}, \mathrm{APCI}^{+}\right)$: found for $[\mathrm{M}+\mathrm{H}]^{+}=756.1390$, calcd for $\mathrm{C}_{34} \mathrm{H}_{33} \mathrm{AuFeNOP}+\mathrm{H}^{+} 756.1387$

Synthesis of $\left(\boldsymbol{R}, \boldsymbol{S}_{\mathrm{p}},\right)-\mathbf{1 0}$. $(R)-\mathbf{9}^{16}(0.2572 \mathrm{~g}, 1.00 \mathrm{mmol})$ was dissolved in diethyl ether $(2 \mathrm{~mL})$ in a flame dried Schlenk tube under an inert atmosphere. $n$-Butyllithium $(0.86 \mathrm{~mL}, 1.20 \mathrm{mmol})$ was added dropwise and the solution stirred at room temperature for $2 \mathrm{~h}$. In a separate dry vessel, mercury(II) chloride $(0.407 \mathrm{~g}, 1.50$ mmol) was heated under high vacuum to ensure it was completely dry and dissolved in the minimum quantity of diethyl ether once cool. After $2 \mathrm{~h}$, the mercury(II) chloride solution was added rapidly to the reaction mixture which was then stirred at room temperature for 30 minutes. The resulting cloudy orange suspension was quenched with saturated sodium hydrogen carbonate followed by the addition of water and diethyl ether. The organic layer was separated and dried with potassium carbonate followed by removal of the solvent in vacuo. Column chromatography $\left(\mathrm{SiO}_{2}, 1 \%\right.$ $\left.\mathrm{NEt}_{3} / \mathrm{Et}_{2} \mathrm{O}\right)$ gave the product as an orange solid $(0.16 \mathrm{~g}, 33 \%)$. Mp:


2935, 2825, 2779, 1446, 920.82. ${ }^{1} \mathrm{H}$ NMR (500 MHz, $\left.\mathrm{CDCl}_{3}\right): 4.37$ $\left(1 \mathrm{H}, \mathrm{d},{ }^{3} \mathrm{HH}_{\mathrm{HH}}=1.8 \mathrm{~Hz}, \mathrm{Cp} H\right), 4.24\left(1 \mathrm{H}, \mathrm{apt},{ }^{3+3}{ }_{\mathrm{HH}}=2.3 \mathrm{~Hz}, \mathrm{Cp} H\right), 4.10$ $(5 \mathrm{H}, \mathrm{s}, \mathrm{CpH}), 4.08-4.07(1 \mathrm{H}, \mathrm{m}, \mathrm{CpH}), 3.94\left(1 \mathrm{H}, \mathrm{q},{ }^{3} \mathrm{JHH}_{\mathrm{H}}=6.7 \mathrm{~Hz}, \mathrm{CH}\right)$, $2.14\left(6 \mathrm{H}, \mathrm{s}, \mathrm{N}\left(\mathrm{CH}_{3}\right)_{2}\right), 1.14\left(3 \mathrm{H}, \mathrm{d},{ }^{3} \mathrm{H}_{\mathrm{HH}}=6.8 \mathrm{~Hz}, \mathrm{CH}_{3}\right) .{ }^{13} \mathrm{C} \mathrm{NMR}(125$ $\left.\mathrm{MHz}, \mathrm{CDCl}_{3}\right)$ : $95.4(\mathrm{CpCC}), 84.0(\mathrm{CpCHg}), 72.5(\mathrm{CpCH}), 69.5\left(\mathrm{C}_{5} \mathrm{H}_{5}\right)$, $69.2(\mathrm{CpCH}), 68.1(\mathrm{CpCH}), 60.0(\mathrm{CH}), 39.4\left(\mathrm{~N}\left(\mathrm{CH}_{3}\right)_{2}\right), 9.2\left(\mathrm{CH}_{3}\right)$. High resolution MS $\left(\mathrm{m} / z, \mathrm{APCI}^{+}\right)$: found for $[\mathrm{M}]^{+}=493.0171$, calcd for $\mathrm{C}_{14} \mathrm{H}_{18} \mathrm{ClFeHgN} 493.0171$.

Synthesis of $\left(\boldsymbol{R}, \boldsymbol{S}_{\mathrm{p}}, \boldsymbol{S}_{\mathrm{Ir}}\right)-\mathbf{1 1}$. $\left(R, S_{\mathrm{p}}\right)-\mathbf{1 0}(0.080 \mathrm{~g}, 0.16 \mathrm{mmol})$, (pentamethylcyclopentadienyl)iridium(III) chloride dimer $(0.065 \mathrm{~g}$, $0.08 \mathrm{mmol})$ and tetrabutylammonium chloride $(0.226 \mathrm{~g}, 0.81$ $\mathrm{mmol}$ ) were added to a flame dried Schlenk tube under an inert atmosphere. Acetone $(5 \mathrm{~mL})$ was added and the resulting brown/orange suspension was allowed to stir at room temperature overnight. The reaction mixture was filtered through Celite ${ }^{\mathrm{TM}}$ using dichloromethane as the eluent and the solvent removed in vacuo. Excess tetrabutylammonium chloride was removed by redissolving the orange residue in hexane (with a small amount of dichloromethane added to aid dissolution) followed by washing with brine $(4 \times 50 \mathrm{~mL})$. The organic layer was dried by filtering through a glass wool pad loaded with magnesium sulfate. Removal of the solvent in vacuo gave a red solid that was recrystallized from hot dichloromethane and hexane yielding red crystals $(0.05 \mathrm{~g}, 50$

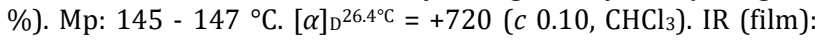
3048, 2966, 2922, 1698, 1458, 1262, 800. ${ }^{1} \mathrm{H}$ NMR $(500 \mathrm{MHz}$, $\left.\left.\mathrm{CDCl}_{3}\right): 4.13\left(1 \mathrm{H}, \mathrm{apt},{ }^{3+3}\right)_{\mathrm{HH}}=2.0 \mathrm{~Hz}, \mathrm{Cp} H\right), 4.06\left(1 \mathrm{H}, \mathrm{d},{ }^{3} J_{\mathrm{HH}}=1.2 \mathrm{~Hz}\right.$, $\mathrm{Cp} H), 3.94(5 \mathrm{H}, \mathrm{s}, \mathrm{Cp} H), 3.69\left(1 \mathrm{H}, \mathrm{d},{ }^{3} J_{\mathrm{HH}}=1.6 \mathrm{~Hz}, \mathrm{CpH}\right), 3.53(1 \mathrm{H}$, brq, $\left.{ }^{3} J_{\mathrm{HH}}=6.8 \mathrm{~Hz}, \mathrm{CH}\right), 3.21\left(3 \mathrm{H}, \mathrm{s}, \mathrm{N}\left(\mathrm{CH}_{3}\right)\right), 3.01\left(3 \mathrm{H}, \mathrm{s}, \mathrm{N}\left(\mathrm{CH}_{3}\right)\right)$, $1.63\left(15 \mathrm{H}, \mathrm{s}, \mathrm{C}_{5}\left(\mathrm{CH}_{3}\right)_{5}\right), 1.22\left(3 \mathrm{H}, \mathrm{d},{ }^{3} \mathrm{JHH}_{\mathrm{HH}}=6.8 \mathrm{~Hz}, \mathrm{CH}_{3}\right) .{ }^{13} \mathrm{C} \mathrm{NMR}$ (125 MHz, $\left.\mathrm{CDCl}_{3}\right): 102.3(\mathrm{CpCC}), 90.1$ (CpClr), $87.2\left(\mathrm{C}_{5}\left(\mathrm{CH}_{3}\right)_{5}\right), 68.5$ $(\mathrm{CpCH}), 68.1\left(\mathrm{C}_{5} \mathrm{H}_{5}\right), 67.6(\mathrm{CpCH}), 63.5(\mathrm{CH}), 60.7(\mathrm{CpCH}), 50.5$ $\left(\mathrm{N}\left(\mathrm{CH}_{3}\right)\right)$, $49.4\left(\mathrm{~N}\left(\mathrm{CH}_{3}\right)\right)$, $9.6\left(\mathrm{C}_{5}\left(\mathrm{CH}_{3}\right)_{5}\right), 9.3\left(\mathrm{CH}_{3}\right)$. High resolution MS $\left(m / z, \mathrm{NSI}^{+}\right):[\mathrm{M}-\mathrm{Cl}]^{+}=584.1581$, calcd for $\mathrm{C}_{24} \mathrm{H}_{33} \mathrm{FeIrN}^{+}$ 584.1586.

Synthesis of $\left(\boldsymbol{R}, \boldsymbol{S}_{\mathbf{p}}\right)-\mathbf{1 3}$. $(R)-12^{18}(0.100 \mathrm{~g}, 0.18 \mathrm{mmol})$ was added to a flame dried Schlenk tube under an inert atmosphere and dissolved in dry diethyl ether (5 mL). sec-Butyllithium (1.4 M in hexanes) (1.23 $\mathrm{mL}, 1.8 \mathrm{mmol})$ was added and the reaction was heated to $40{ }^{\circ} \mathrm{C}$ and allowed to stir for $3 \mathrm{~h}$. In a separate dry vessel, mercury(II) chloride $(0.543 \mathrm{~g}, 2.0 \mathrm{mmol})$ was heated under high vacuum to ensure it was completely dry and dissolved in the minimum quantity of diethyl ether once cool. After $3 \mathrm{~h}$, the mercury(II) chloride solution was added rapidly to the reaction mixture followed by heating at $40{ }^{\circ} \mathrm{C}$ for 15 mins. The resulting cloudy orange suspension was allowed to cool to room temperature, diluted with diethyl ether, and then quenched with saturated sodium hydrogen carbonate. The organic layer was separated and washed with water and then brine, dried over potassium carbonate, and the solvent removed in vacuo. Purification by column chromatography $\left(\mathrm{SiO}_{2}, 50 \% \mathrm{EtOAc} /\right.$ hexane $)$ yielded the product as a yellow solid (0.0395 g, 28\%). Rf 0.18 (50 \% EtOAc/hexane). Mp: $68.8-71.4{ }^{\circ} \mathrm{C}$. $[\alpha]_{D}^{22.6^{\circ} \mathrm{C}}=+16\left(c 0.2, \mathrm{CHCl}_{3}\right)$. IR (film): 3080, 3058, 3029, 2971, 2938, 2868, 2828, 2784, 1597, 1498, 908, 736, 699. ${ }^{1} \mathrm{H}$ NMR (500 $\left.\mathrm{MHz}, \mathrm{CDCl}_{3}\right): 7.49-7.45(8 \mathrm{H}, \mathrm{m}, \mathrm{ArH}), 7.27-7.24(12 \mathrm{H}, \mathrm{m}, \mathrm{Ar} H)$, $4.79\left(1 \mathrm{H}, \mathrm{dd},{ }^{3} J_{\mathrm{HH}}=2.4,{ }^{4} J_{\mathrm{HH}}=1.2 \mathrm{~Hz}, \mathrm{CpH}\right), 4.27\left(1 \mathrm{H}, \mathrm{dd},{ }^{3} J_{\mathrm{HH}}=2.4\right.$, $\left.{ }^{4} J_{\mathrm{HH}}=1.2 \mathrm{~Hz}, \mathrm{Cp} H\right), 4.64\left(1 \mathrm{H}, \mathrm{apt},{ }^{3+3} J_{\mathrm{HH}}=2.4 \mathrm{~Hz}, \mathrm{CpH}\right), 3.04(1 \mathrm{H}$, brq, $\left.{ }^{3} J_{\mathrm{HH}}=6.7 \mathrm{~Hz}, \mathrm{CH}\right), 1.96\left(6 \mathrm{H}, \mathrm{s}, \mathrm{N}\left(\mathrm{CH}_{3}\right)_{2}\right), 0.87\left(3 \mathrm{H}, \mathrm{d},{ }^{3} 3_{\mathrm{HH}}=6.7\right.$ $\left.\mathrm{Hz}, \mathrm{CH}_{3}\right) .{ }^{13} \mathrm{C}$ NMR $\left(125 \mathrm{MHz}, \mathrm{CDCl}_{3}\right): 136.2(\mathrm{ArC}), 128.8(\mathrm{ArC})$, $128.5(\operatorname{ArC}), 126.7(\operatorname{ArC}), 106.7$ (CpCC), 104.7 (CpCHg), 88.9 $(\mathrm{CpCH}), 84.5(\mathrm{CpCH}), 81.9(\mathrm{CpCH}), 75.23\left(\mathrm{C}_{4} \mathrm{Ph}_{4}\right), 55.6(\mathrm{CH}), 39.1$ $\left(\mathrm{N}\left(\mathrm{CH}_{3}\right)_{2}\right)$, $9.8\left(\mathrm{CH}_{3}\right)$. High resolution MS $\left(\mathrm{m} / \mathrm{z}, \mathrm{ASAP}^{+}\right):[\mathrm{M}+\mathrm{H}]^{+}=$ 788.1413, calcd for $\mathrm{C}_{37} \mathrm{H}_{33} \mathrm{ClCoHgN}+\mathrm{H}^{+} 788.1414$.

Iridacycle catalysed reductive amination. To a Schlenk tube was added acetophenone $(0.12 \mathrm{~mL}, 1.00 \mathrm{mmol})$, benzylamine $(0.13 \mathrm{~mL}$, $1.20 \mathrm{mmol})$ and $\left(S, R_{\mathrm{p}}, S_{\mathrm{Ir}}\right)-5-d-6(0.007 \mathrm{~g}, 0.01 \mathrm{mmol})$ followed by dissolution in methanol ( $3 \mathrm{~mL}$ ). A 5:2 mixture of formic acid and triethylamine $(0.5 \mathrm{~mL})$ was then added and the reaction heated to $80{ }^{\circ} \mathrm{C}$ and stirred at this temperature overnight following sealing of the Schlenk tube. After cooling, the reaction was quenched with water, made basic with potassium hydroxide and extracted with ethyl acetate. The organic solvent was removed in vacuo and the residue purified by column chromatography $\left(\mathrm{SiO}_{2}, 10 \%\right.$ EtOAc/hexane) yielding a colorless oil $(0.068 \mathrm{~g}, 32 \%, 0 \%$ ee). Data as previously reported. ${ }^{26}$ Enantiomeric excess determined following acetylation (see supporting information).

Crystal structure analyses - $\left(S, S_{\mathrm{p}}\right)-3 \&\left(S, S_{\mathrm{p}}\right)-5-d-4$

For each sample, a single crystal was mounted on a glass fiber and fixed in the cold nitrogen stream on an Oxford Diffraction Xcalibur3/Sapphire3-CCD diffractometer (at UEA). Intensity data were measured by thin-slice $\omega$ - and $\varphi$-scans. Data were processed using the CrysAlisPro-CCD and - $\mathrm{RED}^{27}$ programs. The structures were determined by the intrinsic phasing routines in the SHELXT program $^{28}$ and refined by full-matrix least-squares methods, on $\mathrm{F}^{2} \mathrm{~s}$, in SHELXL. ${ }^{29}$ The non-hydrogen atoms were refined with anisotropic thermal parameters. Hydrogen atoms were included in idealised positions and their Uiso values were set to ride on the Ueq values of the parent carbon atoms.

In the final difference map, the highest peaks were close to the mercury atoms.

Scattering factors for neutral atoms were taken from 'International Tables'. ${ }^{30}$ Computer programs used in this analysis have been noted above, and were run through WinGX ${ }^{31}$ at the University of East Anglia.

\section{Crystal structure analysis - $\left(R, S_{\mathrm{p},}, S_{\mathrm{Ir}}\right)-11$}

A suitable crystal $(0.130 \times 0.120 \times 0.005) \mathrm{mm}^{3}$ was selected and mounted on a MITIGEN holder in perfluoroether oil on a Rigaku FRE+ equipped with VHF Varimax confocal mirrors and an AFC12 goniometer and HyPix 6000 detector diffractometer. The crystal was kept at $T=100(2) \mathrm{K}$ during data collection. Using Olex2, ${ }^{32}$ the structure was solved with the ShelXT ${ }^{28}$ structure solution program, using the Intrinsic Phasing solution method. The model was refined with version $2014 / 7$ of ShelXL ${ }^{29}$ using Least Squares minimization.

\section{ASSOCIATED CONTENT}

\section{Supporting Information}

The Supporting Information is available free of charge on the ACS Publications website. Copies of the ${ }^{1} \mathrm{H},{ }^{13} \mathrm{C},{ }^{31} \mathrm{P}$ NMR and $\mathrm{X}$ ray crystallography details (PDF file). CCDC 1873232, 1873231 and 1862175 contain supplementary X-ray crystallographic data for $\left(S, S_{\mathrm{p}}\right)-\mathbf{3},\left(S, S_{\mathrm{p}}\right)-5-\mathrm{d}-\mathbf{4}$ and $\left(R, S_{\mathrm{p}}, S_{\mathrm{Ir}}\right)-\mathbf{1 1}$, respectively. This data can be obtained free of charge via http://www.ccdc. cam.ac.uk/conts/retrieving.html, or from the Cambridge Crystallographic Data Centre, Union Road, Cambridge, CB2 1EZ; fax(+44) 1223-336-033 or e-mail: deposit@ccdc.cam.ac. uk. 
The Supporting Information is available free of charge on the ACS Publications website.

\section{AUTHOR INFORMATION}

\section{Corresponding Author}

*Email: Chris.Richards@uea.ac.uk Notes

The authors declare no competing financial interest.

\section{ACKNOWLEDGMENT}

The AI-Chem Channel is thanked for financial support. We also thank the EPSRC National Mass Spectrometry Centre (University of Wales, Swansea).

\section{REFERENCES}

(1) (a) Dupont, J.; Consorti, C. S.; Spencer, J. The Potential of Palladacycles: More Than Just Precatalysts. Chem. Rev. 2005, 105, 2527-2571. (b) Djukic, J.-P.; Sortais, J.-B.; Barloy, L.; Pfeffer, M. Cycloruthenated Compounds - Synthesis and Applications. Eur. J. Inorg. Chem. 2009, 817-853. (c) Michon, C.; MacIntyre, K.; Corre, Y.; Agbossou-Niedercorn, F. Pentamethylcyclopentadienyl Iridium(III) Metallacycles Applied to Homogeneous Catalysis for Fine Chemical Synthesis. Chem. Cat. Chem. 2016, 8, 1755-1762. (d) Wang, C.; Xiao, J. Iridacycles for Hydrogenation and Dehydrogenation Reactions. Chem. Commun. 2017, 53, 3399-3411. (e) Hazari, N.; Melvin, P. R.; Beromi, M. M. Well-Defined Nickel and Palladium Precatalysts for Cross-Coupling. Nat. Rev. Chem. 2017, 1, 0025.

(2) Djukic, J.-P.; Hijazi, A.; Flack, H. D.; Bernardinelli, G. Non-Racemic (Scalemic) Planar-Chiral Five-Membered Metallacycles: Routes, Means, and Pitfalls in their Synthesis and Characterization. Chem. Soc. Rev. 2008, 37, 406-425.

(3) (a) Richards, C. J. in Chiral Ferrocenes in Asymmetric Catalsis: Synthesis and Applications (Eds.: Dai, L.-X., Hou, X.-L) Wiley-VCH, Weinheim, 2010, pp. 337-368. (b) Nomura, H.; Richards, C. J. Allylic Imidate Rearrangements Catalyzed by Planar Chiral Palladacycles. Chem. Asian J. 2010, 5, 1726-1740.

(4) (a) Stevens, A. M.; Richards, C. J. Synthesis and Highly Diastereoselective Palladation of ( $\eta^{5}$-(S)-2-(4-Methylethyl)oxazolinylcyclopentadienyl) ( $\eta^{4}$-tetraphenylcyclobutadiene)cobalt. Organometallics 1999, 18, 1346-1348. (b) Xia, J.-B.; You, S.-L. Carbon-Carbon Bond Formation through Double $\mathrm{sp}^{2} \mathrm{C}-\mathrm{H}$ Activations: Synthesis of Ferrocenyl Oxazoline Derivatives. Organometallics 2007, 26, 48694871. (c) Cassar, D. J.; Roghzai, Villemin, D.; Horton, P. N.; Coles, S. J.; Richards, C. J. Chirality Control in Planar Chiral Cobalt Oxazoline Palladacycles. Organometallics 2015, 34, 2953-2961.

(5) (a) Wehman-Ooyevaar, I. C. M.; Vedral, J. A.; Jastrzebski, J. T. B. H.; Grove, D. M.; van Koten, G. Novel Rhodate and Iridate Complexes Containing C,N Chelating Arylamine Ligand Systems. J. Organomet. Chem. 1993, 451, 195-204. (b) Pérez, J.; Riera, V.; Rodríguez, A.; Miguel, D. Synthesis and Structure of the First Ruthenated Benzodiazepines. Organometallics 2002, 21, 5437-5438.

(6) (a) Meneghetti, M. R.; Grellier, M.; Pfeffer, M. Dupont, J.; Fischer, J. Synthesis of Configurationally Stable, Optically Active Organocobalt Compounds. Organometallics 1999, 18, 5560-5570. (b) Djukic, J.-P.; Berger, A.; Duquenne, M.; Pfeffer, M.; de Cian, A.; KyritsakasGruber, N.; Vachon, J.; Lacour, J. Syntheses of Nonracemic OrthoMercurated and Ortho-Ruthenated Complexes of 2-[Tricarbonyl $\left(\eta^{6}\right.$-phenyl)chromium]pyridine. Organometallics 2004, 23, 5757-5767.

(7) Arthurs, R. A.; Ismail, M.; Prior, C. C.; Oganesyan, V. S.; Horton, P. N.; Coles, S. J.; Richards, C. J. Enantiopure Ferrocene-Based Planar-Chiral Iridacycles: Stereospecific Control of Iridium-Centred Chirality. Chem. Eur, J. 2016, 22, 3065-3072.

(8) Arthurs, R. A.; Prior, C. C.; Hughes, D. L.; Oganesyan, V. S.; Richards, C. J. Enantiopure Planar Chiral and Chiral-at-Metal Iridacycles
Derived from Bulky Cobalt Sandwich Complexes. Organometallics 2018, 37, 4204-4212.

(9) Hegedus, L. S. in Comprehensive Organometallic Chemistry II, Vol. 12 (Eds.: Abel, E. W.; Stone, F. G. A.; Wilkinson, G) Pergamon, Oxford, 1995, pp. 1-8.

(10) Abbenhuis, H. C. L.; Pfeffer, M.; Sutter, J. P.; de Cian, A.; Fischer, J.; Ji, H. L.; Nelson, J. H. Carbon-Carbon and Carbon-Nitrogen Bond Formation Mediated by Ruthenium(II) Complexes: Synthesis of $(1 H)$-Isoquinolinium Derivatives. Organometallics 1993, 12, 44644472.

(11) Sammakia, T.; Latham, H. A. Ligand Effects on the Stereochemistry of the Metalation of Chiral Ferrocenyloxazolines. J. Org. Chem. $1995,60,6002-6003$.

(12) Arthurs, R. A.; Horton, P. N.; Coles, S. J.; Richards, C. J. Metallocene to Metallocene Conversion. Synthesis of an Oxazoline-Substituted Pentamethyliridocenium Cation from a Ferrocenyloxazoline. Chem. Commun. 2016, 7024-7027.

(13) Arthurs, R. A.; Richards, C. J. Deuterium as a Stereochemically Invisible Blocking Group for Chiral Ligand Synthesis. Org. Lett. 2017, 19, 702-705.

(14) Gorunova, O. N.; Novitskiy, I. M.; Grishin, Y. K.; Gloriozov, I. P.; Roznyatovsky, V. A.; Khrustalev, V. N.; Kochetkov, K. A.; Dunina, V. V. When Applying the Mercury Poisoning Test to Palladacycle-Catalyzed Reactions, One Should Not Consider the Common Misconception of Mercury(0) Selectivity. Organometallics 2018, 37, 28422858.

(15) Holz, J.; Garcia, M. A.; Frey, W.; Krupp, F.; Peters, R. Diastereoselective Synthesis, Structure and Reactivity Studies of Ferrocenyloxazoline Gold(I) and Gold(II) Complexes. Dalton Trans. 2018, 47, 3880-3905.

(16) Marquarding, D.; Klusacek, H.; Gokel, G.; Hoffmann, P.; Ugi, I. Correlation of Central and Planar Chirality in Ferrocene Derivatives. J. Am. Chem. Soc. 1970, 92, 5389-5393.

(17) Reported previously but lacking a detailed experimental procedure and characterisation data. See: Sokolov, V. I.; Troitskaya, L. L.; Reutov, O. A. Asymmetric Induction in the Course of Internal Palladation of Enantiomeric 1-Dimethylaminoethylferrocene. J. Organomet. Chem. 1977, 133, C28-C30.

(18) Arthurs, R. A.; Horton, P. N.; Coles, S. J.; Richards, C. J. Stereoselective and Stereospecific Reactions of Cobalt Sandwich Complexes: Synthesis of a New Class of Single Enantiomer Bulky Planar Chiral P-N and P-P Ligands. Chem. Eur. J. 2018, 24, 4310-4319.

(19) (a) Martin, G. C.; Boncella, J. M. Nucleophilic Addition to Coordinated Imines: Diastereoselective Synthesis of the Ruthenium Amide Complexes $\left(\eta^{6}-\mathrm{C}_{6} \mathrm{Me}_{6}\right) \mathrm{RuN}(\mathrm{Ph}) \mathrm{CRR}^{\prime} \mathrm{C}_{6} \mathrm{H}_{4}\left(\mathrm{PMe}_{3}\right)$. Organometallics 1989, 8, 2968-2970. (b) Martin, G. C.; Boncella, J. M.; Wucherer, E. J. Synthesis of Ruthenium Amide Complexes by Nucleophilic Attack on Ortho-Metalated Imine Ligands. Organometallics 1991, 10, 2804-2811. (c) Attar, S.; Nelson, J. H.; Fischer, J.; de Cian, A.; Sutter, J.-P.; Pfeffer, M. Metallacycles with Stereogenic Metal Centers: Synthesis and Characterization of Diastereomeric Cycloruthenated Chiral Amines. Organometallics 1995, 14, 45594569. (d) Attar, S.; Catalano, V. J.; Nelson, J. H. Diastereoselectivity of Chloride Substitution Reactions of Cycloruthenated $(R)_{\mathrm{C}-}(+)-$ and $(S)_{\mathrm{c}-}(-)$-Dimethyl(1-phenylethyl)amine. Organometallics 1996, 15, 2932-2946. (e) Hansen, H. D.; Maitra, K.; Nelson, J. H. Chloride Substitution Reactions of Cycloruthenated $(R)_{\mathrm{C}-}(+)-N, N-$ Dimethyl(1-phenylethyl)amine with Pseudohalides: Ruthenium Atom Stereochemistry. Inorg. Chem. 1999, 38, 2150-2156. (f) Gül, N.; Nelson, J. H. Synthesis, Characterization, and Diastereoselectivity of Chloride Substitution Reactions of Cycloruthenated $(R)_{\mathrm{c}-}(+)-$ $N, N$-Dimethyl- $\alpha$-(2-naphthyl) Ethylamine. Organometallics 1999, 18, 709-725. (g) Gül, N.; Nelson, J. H. Ruthenacycles with Stereogenic Metal Centers: Synthesis and Characterization of Cycloruthenated $(R)_{\mathrm{C}-}(+)-N, N$-Dimethyl- $\alpha$-(2-naphthyl) ethylamine (TMNA); Crystal Structure of [ $\left.\left(\eta^{6}-\mathrm{C}_{6} \mathrm{H}_{5} \mathrm{Me}\right) \mathrm{Ru}(\mathrm{TMNA})(\mathrm{X})\right],(\mathrm{X}=\mathrm{Cl}, \mathrm{Br}, \mathrm{I})$. Polyhedron 1999, 18, 1835-1843. (h) Ritleng, V.; Bertani, P.; Pfeffer, M.; Sirlin, C.; Hirschinger, J. Optically Active Ortho-Metalated HalfSandwich Ruthenium Complexes: Solid-State NMR as a Convenient 
Tool To Analyze Mixtures of Diastereomers. Inorg. Chem. 2001, 40, 5117-5122. (i) Sortais, J.-B.; Ritleng, V.; Voelklin, A.; Holuigue, A.; Smail, H.; Barloy, L.; Sirlin, C.; Verzijl, G. K. M.; Boogers, J. A. F.; de Vries, A. H. M.; de vries, J. G.; Pfeffer, M. Cycloruthenated Primary and Secondary Amines as Efficient Catalyst Precursors for Asymmetric Transfer Hydrogenation. Org. Lett. 2005, 7, 1247-1250. (j) Sortais, J.-B.; Pannetier, N.; Holuigue, A.; Barloy, L.; Sirlin, C.; Pfeffer, M.; Kyritsakas, N. Cyclometalation of Primary Benzyl Amines by Ruthenium(II), Rhodium(III), and Iridium(III) Complexes. Organometallics 2007, 26, 1856-1867. (k) Sortais, J.-B.; Pannetier, N.; Clément, N.; Barloy, L.; Sirlin, C.; Pfeffer, M.; Kyritsakas, N. Cyclometalation of Secondary Benzyl Amines by Ruthenium(II) Complexes. Organometallics 2007, 26, 1868-1874. (l) Pannetier, N.; Sortais, J.-B.; Dieng, P. S.; Barloy, L.; Sirlin, C.; Pfeffer, M. Kinetics and Mechanism of Ruthenacycle-Catalyzed Asymmetric Hydrogen Transfer. Organometallics 2008, 27, 5852-5859. (m) Arthurs, R. A.; Horton, P. N.; Coles, S. J.; Richards, C. J. Phenyl vs. Ferrocenyl Cyclometallation Selectivity: Diastereoselective Synthesis of an Enantiopure Iridacycle. Eur. J. Inorg. Chem. 2017, 229-232. (n) Chen, H. J.; Teo, R. H. X.; Li, Y.; Pullarkat, S. A.; Leung, P.-H. Stereogenic Lock in 1-Naphthylethanamine Complexes for Catalyst and Auxiliary Design: Structural and Reactivity Analysis for Cycloiridated Pseudotetrahedral Complexes. Organometallics 2018, 37, 99-106. (20) The exceptions are $N$-heterocyclic ligated iridacycles. See: Sabater, S.; Baya, M.; Mata, J. A. Highly Active Cp*Ir Catalyst at Low Temperatures Bearing an N-Heterocyclic Carbene Ligand and a Chelated Primary Benzylamine in Transfer Hydrogenation. Organometallics 2014, 33, 6830-6839.

(21) Arrayás, R. G.; Mancheño, O. G.; Carretero, J. C. First Planar Chiral Bidentate Ligand Based on a ( $\eta^{5}$-Cyclopentadienyl) $\left(\eta^{4}\right.$-cyclobutadiene)cobalt Backbone: High Efficiency in Enantioselective Palladium-Catalyzed Allylic Substitutions. Chem. Commun. 2004, 16541655.
(22) Wang, C.; Xiao, J. Iridacycles for Hydrogenation and Dehydrogenation Reactions. Chem. Commun. 2017, 53, 3399-3411.

(23) Chen, H.-Y. T.; Wang, C.; Wu, X.; Jiang, X.; Catlow, C. R. A.; Xiao, J. Iridicycle-Catalysed Imine Reduction: An Experimental and Computational Study of the Mechanism. Chem. Eur. J. 2015, 21, 1656416577.

(24) In additional investigations, the attempted reduction of acetophenone was investigated with (a) $\mathrm{KO} t$ - $\mathrm{Bu}$ in $i$-PrOH in the presence of $1 \mathrm{~mol} \%$ of $\left(S, S_{\mathrm{p}}, \mathrm{RIr}\right)-5$ at $80^{\circ} \mathrm{C}$ and (b) $\mathrm{Et}_{3} \mathrm{SiH}$ in $\mathrm{CH}_{2} \mathrm{Cl}_{2}$ in the presence of $0.5 \mathrm{~mol} \%\left(S, S_{\mathrm{p}}, R_{\mathrm{Ir}}\right)-5$ and $1 \mathrm{~mol} \% \mathrm{NaBArF}_{24}$ at RT and then $40^{\circ} \mathrm{C}$. Both resulted in essentially no reaction $(<1 \%)$.

(25) Sammakia, T.; Latham, H. A.; Schaad, D. R. Highly Diastereoselective Ortho Lithiations of Chiral Oxazoline-Substituted Ferrocenes. J. Org. Chem. 1995, 60, 10-11.

(26) Wang C.; Pettman A.; Basca J.; Xiao J. A Versatile Catalyst for Reductive Amination by Transfer Hydrogenation. Angew. Chem. Int.l Ed. 2010, 49, 7548-7552.

(27) Programs CrysAlisPro, Oxford Diffraction Ltd., Abingdon, UK (2010).

(28) Sheldrick, G. M. SHELXT - Integrated space-group and crystalstructure determination. Acta Cryst. 2015, A71, 3-8.

(29) Sheldrick, G. M. Crystal Structure Refinement with SHELXL. Acta Cryst. 2015, C71, 3-8.

(30) 'International Tables for X-ray Crystallography', Kluwer Academic Publishers, Dordrecht, 1992. Vol. C, pp. 500, 219 and 193.

(31) Farrugia, L. J. WinGX and ORTEP for Windows: an Update. J. Appl. Cryst. 2012, 45, 849-854.

(32) Dolomanov 0. V.; Bourhis L. J.; Gildea R. J.; Howard J. A. K.; Puschmann H. OLEX2: A Complete Structure Solution, Refinement and Analysis Program. J. Appl. Cryst. 2009, 42, 339-341.

Graphic entry for Table of Contents

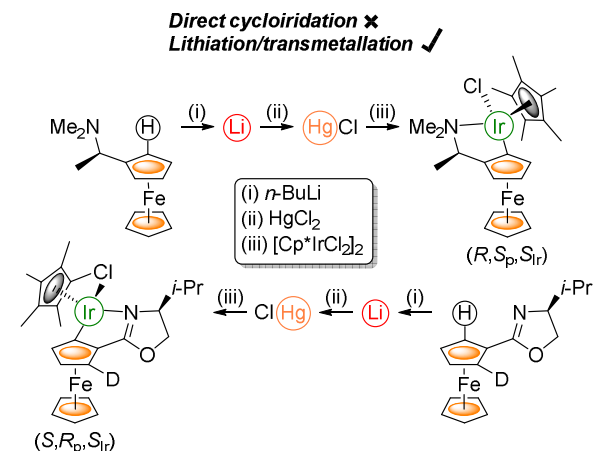

